\title{
Validating the Islamic Orientation Scale with Grade Four Senior High Schools Students and Comparing Its Underlying Factors with Those of Pilgrims of Imam Reza Shrine: A Schema-Based Approach
}

\author{
Beheshteh Shakhsi Dastgahian1, Ebrahim Khodadady ${ }^{*}$ \\ ${ }^{1}$ Ferdowsi University of Mashhad International Branch, Mashhad, Iran \\ ${ }^{2}$ Ferdowsi University of Mashhad, Mashhad, Iran \\ Email: "ekhodadady@ferdowsi.um.ac.ir
}

Received 7 October 2015; accepted 22 October 2015; published 27 October 2015

Copyright (C) 2015 by authors and OALib.

This work is licensed under the Creative Commons Attribution International License (CC BY). http://creativecommons.org/licenses/by/4.0/

(c) (†) Open Access

\section{Abstract}

This study aimed to determine the factors underlying grade four senior high school (G4SHS) students' Islamic orientation and compare them with those of pilgrims who visited and prayed in Imam Reza Shrine in Mashhad, Iran. To this end the 44-sentence Islamic Orientation Scale (IOS) developed by Khodadady and Bagheri [1] was administered to 453 students. The subjection of the data to Principal Axis Factoring and Varimax with Kaiser Normalization showed that eight factors underlie the scale, i.e., social, inspirational, observant, sacrificial, humanitarian, theo-pacific, inquisitive and charitable. Based on the microstructural approach of schema theory, the words used in the IOS were treated as representatives of basic concepts called schemata. These concepts combined with each other within the linguistic context of each sentence to produce a broader concept called species. The species represented by the sentences which loaded acceptably on the eight factors represented genera as the second broadest concepts constituting the domain of Islamic orientation. The domain is thus treated as the broadest concept or construct which is measured by the scale. The schema-based analysis of results showed that G4SHS students differed from pilgrims in their Islamic orientation because six out of eight genera constituting the domain differed from each other in their species, i.e., social, inspirational, observant, sacrificial, inquisitive and charitable. The results are discussed and suggestions are made for future researcher.

\section{Keywords}

Islam, Orientation, Domain, Genus, Species, Schemata

${ }^{*}$ Corresponding author.

How to cite this paper: Dastgahian, B.S. and Khodadady, E. (2015) Validating the Islamic Orientation Scale with Grade Four Senior High Schools Students and Comparing Its Underlying Factors with Those of Pilgrims of Imam Reza Shrine: A SchemaBased Approach. Open Access Library Journal, 2: e1892. http://dx.doi.org/10.4236/oalib.1101892 


\section{Introduction}

Allport and Ross [2] (henceforth A \& R) developed a psychological measure called Religious Orientation Scale (ROS) in order to address human religiosity in relation to ethnic prejudice from a dichotomous perspective. They composed ten sentences to assess what they believed to be intrinsic motivation and another set of ten sentences to measure extrinsic motivation. A \& R administered their 20-item ROS to 309 individuals belonging to six church groups and based on the participants' responses concluded that “(a) on the average churchgoers are more prejudiced than nonchurchgoers; (b) the relationship is curvilinear; (c) people with an extrinsic religious orientation are significantly more prejudiced than people with an intrinsic religious orientation” (p. 432).

Many researchers have followed A \& R and treated religious orientation as a two-dimensional construct. Herek [3], for example, administered the A \& R's 20-item ROS along with a seven-item measure of symbolic racism to 126 university students in America and found that extrinsic orientation was "positively correlated with racism, while an intrinsic orientation was not" (p. 34). Similarly, Almeida [4] administered the ROS along with Weiten's [5] [6] Pressure Inventory (Form III) to 76 undergraduate engineering students in South Africa and concluded that "religious affiliation showed a significant difference in terms of intrinsic religious orientation, self imposed pressure, pressure in intimate relations and total pressure” (p. ii).

Treating religiosity as a bipolar construct has also been extended to participants whose language and religion are different from the English speaking Christians whose religious orientation was first established by A \& R without any factorial analysis. Ghorbani et al. [7], however, translated the A \& R's 20-item ROS into Persian and administered it to 187 Iranian university students and subjected their responses to principal component analysis (PCA) and Varimax with Kaiser Normalization (VKN) and extracted "two factors with eigenvalues greater than one" (p. 84). Unfortunately, the researchers provided their readers neither with the items constituting the ROS nor with the loading of each item on their two rotated factors.

Similar to Kirkpatrick [8], Brewczynski and MacDonald [9], nonetheless, took the sentence representing the species "one reason for my being a church member is that such membership helps to establish a person in the community" from Feagin [10] and added it to the A \& R's 20-item ROS. They translated the scale into Polish and administered it to 303 Catholic Polish university students. When Brewczynski and MacDonald subjected their data to confirmatory factor analysis (CFA), instead of two they extracted three factors and concluded that "the pattern of item cross-loadings revealed that the factorial structure of the ROS is complex and suggests that the constructs purportedly assessed by the instrument may not be invariant across cultures” (p. 63).

Following Brewczynski and MacDonald [9], Khodadady and Golparvar [11] translated the 21-item ROS into Persian and administered it to 329 undergraduate university students majoring in agriculture, architecture, English language and literature and theology in an Iranian state university in Mashhad, Iran. Instead of CFA, they subjected their data to the PCA, the Maximum Likelihood (ML) and Principal Axis Factoring (PAF) and rotated the extracted latent variables with VKN. Their results showed that all the three methods of factor analysis yielded four factors, challenging A \& R's logical dichotomization of religious orientation into intrinsic and extrinsic motivations.

As brought up by Khodadady and Saadi [12], the 21-item ROS is religion-specific, i.e., Christianity, because of its item three, i.e., the prayers I say when I am alone carry as much meaning and personal emotion as those said by me during services. The schema "services", according to Fairchild [13] involves employing music and songs in most churches. Neither music nor songs are, however, allowed within mosques in Islam. It is not known what researchers who administered the ROS to Muslim participants have done with item three. Ghorbani et al. [7], for example, did not provide their readers with their translation of this particular item. Khodadady and Golparvar [11], however, replaced the schema "services" with "in the presence of people" resulting in the setence "the prayers I say when I am alone carry as much meaning and personal emotion as those said by me in the presence of people".

Khodadady and Bagheri [14] added 12 more items to the 21-item ROS to accommodate the points their participants had raised in their class discussion of religious orientation. They administered the enlarged 33-item ROS to 536 undergraduate university students majoring in architecture, engineering English language and lite- 
rature, psychology, Russian language and literature, science and theology to determine what factors underlay their religious orientation. For extracting the factors they adopted the PAF because it neither inflates the items loading on the first factor nor distorts the magnitude of items which load acceptably on other factors when they are rotated and thus provides a more accurate measure of whatever factors instruments such as the ROS are designed to measure.

The results obtained by Khodadady and Bagheri [13] showed that similar to Khodadady and Golparvar's [11] findings, item three, "the prayers I say when I am alone carry as much meaning and personal emotion as those said by me in the presence of people," did not load on any of the seven rotated factors they extracted from the 33-item ROS. Neither did the item load on any of the six factors Khodadady, Mousavi and Sarraf [15] extracted from the scale when they administered it to 780 grade three senior high school (G3SHS) students in the same city and country, indicating that the species expressed by the item was irrelevant to the domain of religious orientation within an Islamic context. Item three was, therefore, removed from the 33-item ROS.

Since shrines are "the locations of supplication and worship" (Newby [16], p. 177) in all religions including Islam and provide researchers with objective indicators of a given person's religiosity, Khodadady and Bagheri [1] (henceforth K \& B) administered the 32-item ROS to several national and international pilgrims to Imam Reza Shrine (IRS) in Mashhad, Iran, and asked them not only to read the items and write down the missing sentences which described what they themselves did as part of their religious commitment in their daily life but also to raise whatever questions they had regarding the sentences. Based on the pilgrims' written sentences and oral questions, K \& B added 12 new sentences to the battery and revised some of the 32 items to remove their ambiguity as reflected in the questions raised by the pilgrims. To differentiate their 44-item scale from other scales it is referred to as Islamic Orientation Scale (IOS) in this study.

In order to validate the IOS, K \& B first analyzed its constituting words linguistically. The analysis showed that the scale consists of 465 words among which the majority were nouns $(n=110,23.7 \%)$. However, when the IOS was administered to 749 pilgrims of Imam Reza Shrine (henceforth pilgrims), four sentences did not load acceptably, i.e., 0.32 and higher, on any of ten factor factors extracted from their responses. The linguistic analysis of the 40 sentences loading acceptably on the factors reduced the number of words to 413, most of which were again nouns ( $n=96,23.2 \%$ ). The linguistic analysis thus indicated that the Islamic orientation of pilgrims sampled by K \& B should be discussed with 413 words rather than 465 .

Based on the microstructural approach of schema theory, K \& B argued the 465 words comprising the IOS represent the basic concepts or schemata upon which the domain of the designer-based Islamic orientation rests. These schemata relate to each other in a specific way within the linguistic context of 44 sentences in which they occur and thus each sentence brings up a single broader-than-schema concept called species. K \& B further argued that the validity of the schemata and species depended not only on the designer of the IOS but also on the participants to whom it is administered.

The administration of IOS to pilgrims, for example, showed that out of 44 species brought up by K \& B four species were irrelevant to their domain of Islamic orientation because they did not load acceptably on any of the ten factors extracted from their responses. They believed that each of the ten factors upon which the 40 sentences of IOS loaded acceptably represent a unique participant-dependent concept called genus. The domain of pilgrims' Islamic orientation thus consisted of ten genera: inspirational, intrinsic, congregational, social, ceremonial, sacrificial, theo-pacific, humanitarian, concessional and observant. The genera in their turn consisted of 40 species and 413 schemata.

\subsection{Inspirational Genus}

Pilgrims having inspirational genus inspire themselves by attending the ceremony of the Night of Qadr, i.e., the night at which the Quran was revealed to the prophet Mohammad. They also actively attend the mourning ceremonies held for the prophet's household, believe in the effect of alms-giving in shielding against catastrophes and problems, visit the prophet's descendents on Id al-Ghadir, i.e., the 18th of Dhul-Hajjah on which the prophet appointed Ali Ibn Abi Talib as his successor and all Muslims attending the last pilgrimage including Abu Bakr, Umar, and Uthman swore allegiance saying "Well done Ibn Abi Talib! Today you became the leader (Mawla) of all believing men and women" (al-Razi [17], pp. 49-50), observe Ghusl, i.e., the complete ritual washing of the body to pray, and attend Friday prayers. And finally they consume Halal food when travelling to different countries. 


\subsection{Intrinsic Genus}

Similar to the inspirational genus, the intrinsic genus consists of six species characterizing pilgrims as believers who read literature about faith or religion. They are keenly aware of the presence of God or the Divine Being and believe that accepting Islam must be research-based. They treat religion specifically because it answers many questions about the meaning of their life. It should, therefore, be carried over into all other dealings, e.g., social, economic and political, in life. They pray because everyone is taught to pray.

\subsection{Congregational Genus}

As the third factor underlying the IOS, congregational genus consists of four species whose name is taken from the species, "it is important and necessary to give priority to everyday congregations" having the highest loading on the factor (0.58). Congregationally motivated pilgrims become a member of mosque to establish themselves in the community. They attach more importance to religious trips than to tourism and allocate some money to help charitable organizations.

\subsection{Social Genus}

As the fourth four-sentence factor underlying the IOS, social genus portrays the pilgrims as believers who consider mosques as the most important places where good social relationships are formed. They adopt religious beliefs as reasons underlying their whole approach to life. They attend mosques if unavoidable circumstances do not prevent it and take part in religious ceremonies because they are congenial social activities.

\subsection{Ceremonial Genus}

Five-species ceremonial genus of religious orientation as measured by the IOS, typifies pilgrims as Muslims who participate in ceremonies celebrating the birthdays of the Prophet and his household, join religious groups such as those memorizing and reciting the Quran, participate in prayers offered at Id al-Ghadir and Id al-Adha, attend weekly ceremonies in which supplications such as the one Ali Ibn Abi Talib taught to Komeil Ibn Ziyad (Ghomi [18]) and participate in mourning ceremonies particularly in the lunar months of Moharram and Safar. These two months, according to Al-Islam Organization [19], "offer the yearly opportunity to commemorate the martyrdom of al-Husayn ibn Ali (A), the grandson of the Prophet (S) and the third Imam of the Shiite Muslims, at Karbala' on the tenth of Muharram in the year 61” (p. 16).

\subsection{Sacrificial Genus}

The four sentences loading on the sixth factor extracted from the IOS bring up the sacrificial genus of Islamic orientation domain within the religious setting of IRS. The pilgrims of this particular shrine reveal their sacrificial dimension of religiosity by sacrificing an animal on Id al-Adha, i.e., "the feast of sacrifice, celebrated throughout the Muslim world to mark the end of the annual pilgrimage” ([16], p. 95), and other occasions, consuming sacrificed meat for its religious effect, donating on religious occasions, and trying to carry the Quran under all conditions.

\subsection{Theo-Pacific Genus}

The theo-pacific genus of religious orientation characterizes the pilgrims of IRS in three species as believers who accept that religion offers comfort when sorrows and misfortune strike. They pray in order to secure a happy and peaceful life. They also pray to gain relief and protection (from spiritual problems).

\subsection{Humanitarian Genus}

Compared to inspirational, intrinsic, congregational, social, ceremonial, sacrificial, and theo-pacific genera, humanitarian genus is less complex in scope because it consists of only two species. Humanitarian pilgrims of IRS "support the deprived people" and "visit patients" as part of their religious duty.

\subsection{Concessional Genus}

Among the ten genera constituting the domain of pilgrims' religious orientation, the four-species concessional 
genus contributes little to the domain because it has the lowest correlation with the IOS $(r=0.08, \mathrm{p}<0.05)$ and characterizes the pilgrims as individuals who believe that religious considerations should not be allowed to influence everyday affairs. They lead a moral life without attaching any importance to what religion one believes, accept that in spite of believing in religion, there are many more important things in life and finally obtain information on other religions besides Islam.

\subsection{Observant Genus}

Similar to humanitarian genus, observant genus consists of two species. It characterizes pilgrims as individuals who believe that both men and women should observe Hijab, keep the account of their wealth and possessions and pay their Zakat and Khums. The former is the money "calculated at 2.5 percent of accrued wealth" ([20], p. 19) and paid to the needy, and the latter is " $20 \%$ tax levied on certain items" ([21], p. 91).

As described above the validity of genera forming the domain of Islamic orientation depends on their constituting species and schemata. If schemata represent dynamic concepts which evolve throughout individuals' lives, particularly when they are combined with each other to produce broader cognitive concepts [22], then the species of which they form a part must vary in terms of genera upon which they load acceptably. The present study has, therefore, been designed to test the hypothesis that grade four senior high school (G4SHS) students' domain of Islamic orientation differs from that of pilgrims in terms of its constituting schemata, species and genera.

\section{Methodology}

\subsection{Participants}

Four hundred fifty three, 362 female (79.9\%) and 91 (20.1\%) male, G4SHS students took part in this study voluntarily. Their age ranged between 15 and 20 (Mean $=17.44, \mathrm{SD}=0.58$ ). They had registered in four state schools located in educational distracts of two, three, four and seven in Mashhad, Iran. They were majoring in Humanities ( $n=39,8.6 \%)$, Sciences $(n=222,49.0 \%)$, Mathematics $(n=178,39.3 \%)$, and Vocational Studies $(n=14,3.1 \%)$. They spoke Persian $(n=445,98.2 \%)$, Turkish $(n=6,1.3 \%)$, Kurdish $(n=1,0.2 \%)$, and Lori $(n$ $=1,0.2 \%)$ as their mother language.

\subsection{Instruments}

Two instruments were employed: a Demographic Scale and Islamic Orientation Scale.

\subsubsection{Demographic Scale}

A Demographic Scale (DS) consisting of seven short answer questions and multiple choice items was developed to collect the data related to the participants' age, school name, school type, district name, mother language, gender, and field of study. It formed the first part of the booklet in which the IOS was given as its second part.

\subsubsection{Islamic Orientation Scale}

The Persian Islamic Orientation Scale (IOS) developed by K \& B was employed in this study. It consists of 44 sentences. Each sentence is introduced by the incomplete clause, "It is necessary and important..." to draw the participants' attention to the necessity and importance of words comprising each sentence. The words represent schemata whose specific combination with each other in a sentence generates the broader concept of species represented by that sentence. The first sentence, for example, comprises 15 schemata, i.e., "All”, "And”, "Carried over”, “Dealings”, “e.g.”, “Economic”, “In”, “Into”, “Is”, “Life”, “Other”, “Political”, “Religion”, “Social”, and "That". Their specific syntactic ordering within the domain of Islamic orientation reads, "That religion is carried over into all other dealings, e.g., social, economic and political, in life.”

The participants were required to read each of the 44 sentences carefully and decide whether they "strongly agreed”, "agreed”, "had no idea”, “disagreed” or "strongly disagreed” with the species brought up by each sentence. When K \& B administered the IOS to 749 pilgrims and subjected their collected data to PAF and VKN analyses their results showed that sentences 4, 20, and 22 did not load acceptably on any factors and sentence 17 had an acceptable but negative loading on factor two. They concluded that the species represented by sentences 4, 17, 20 and 22 did not contribute to pilgrims' domain of Islamic orientation. Their reported reliability coefficients for the 10 factors representing inspirational, intrinsic, congregational, social, ceremonial, sacrificial, 
theo-pacific, humanitarian, concessional and observant genera were $0.79,0.68,0.63,0.69,0.7,0.64,0.62,0.63$, 0.47 , and 0.59 , respectively.

\subsection{Procedure}

Upon having the Persian DS and IOS printed and copied in adequate numbers, the first researcher contacted her colleagues in four educational districts of Mashhad, Iran, and asked for their cooperation. After explaining the importance of Islamic orientation and its possible relevance to G4SHS students' school achievement, they agreed to talk to their students and encourage them to participate in the study. After securing their students' oral consent to take the IOS on a certain date, the researcher attended the schools and distributed the scales in person. Since the DS and IOS were both in Persian, no particular questions were raised during their administration. It took about 20 minutes for the participants to complete the scales.

\subsection{Data Analysis}

The values of 5, 4, 3, 2 and 1 were assigned, respectively, to "strongly agree”, "agree”, "have no idea”, "disagree" or "strongly disagree" with which each of the 44 sentences of the IOS were presented to run descriptive statistical analyses on the sentences and factors upon which they had loaded acceptably. For estimating the internal consistency of the IOS and its underlying factors Cronbach's Alpha was utilized. For extracting and rotating the factors, the PAF and VKN, were applied to data, respectively. For determining the number of factors, eigenvalues of one and higher were adopted as the main criterion. Tabachnick and Fidell [23] were followed and sentences loading 0.32 and higher, on a given factor were treated as its constituting sentences. If any sentence loaded acceptably on more than one factor, its highest positive loading was adopted as an evidence of its unique contribution to the factor upon which it had loaded and its lower cross loadings were removed from the list of sentences loading acceptably on other factors. Sentences loading acceptably but negatively on any factor were also removed from the structure of factors because of their irrelevance to the concept represented by those factors. All the statistical analyses were conducted via the IBM SPSS Statistics 20 to explore the hypotheses below.

H1. The number of factors extracted from G4SHS students' responses differs from those of pilgrims.

H2. The sentences constituting the factors underlying G4SHS students and pilgrims' Islamic orientation differ from each other in number.

H3. The number of words comprising the IOS changes when it is taken by G4SHS students and pilgrims.

H4. The relationships between religious domain and its constituting genera differ from G4SHS students to pilgrims.

\section{Results}

To determine the adequacy of sample to whom the IOS was administered in this study, the KMO and Bartlett's Test were run. As can be seen in Table 1 the KMO value obtained in this study (0.914) is almost the same as the value reported by K \& B, i.e., 0.913. Since the KMO value is in.90s, it shows that the IOS provides a "marvellous" (Kaiser [24] cited in DiLalla \& Dollinger [25], p. 250) measure of G4SHS students' religious orientation. As it can also be seen in Table 1, the Bartlett's Test of Sphericity is significant $\left(X^{2}=7393.631, \mathrm{df}=946, \mathrm{p}<\right.$ 0.000 ), indicating that the correlation matrix produced by factor analysis was not an identity matrix and it could therefore be run on the data collected.

Table 2 presents the rotated factor matrix of sentences comprising the IOS. As can be seen, 41 sentences loaded acceptably on ten factors. However, while sentences 1, 5, 6, 7, 8, 9, 13, 16, 23, 27, 31, and 36 cross loaded on another factor, sentences 14, 17 and 19 loaded acceptably but negatively on factor four. When low but

Table 1. KMO and Bartlett's test of IOS.

\begin{tabular}{|c|c|c|}
\hline & Khodadady \& Bagheri, 2014 & Present Study \\
\hline Kaiser-Meyer-Olkin Measure of Sampling Adequacy & 0.913 & 0.914 \\
\hline Approx. Chi-Square & 10011.723 & 7393.631 \\
\hline \multirow[t]{2}{*}{ Bartlett's Test of Sphericity } & 946 & 946 \\
\hline & 0.000 & 0.000 \\
\hline
\end{tabular}


Table 2. Rotated Factor Matrix ${ }^{\mathrm{a}}$ of Sentences (Ss) comprising the IOS.

\begin{tabular}{|c|c|c|c|c|c|c|c|c|c|c|}
\hline \multirow{2}{*}{ Ss } & \multicolumn{10}{|c|}{ Factors } \\
\hline & 1 & 2 & 3 & 4 & 5 & 6 & 7 & 8 & 9 & 10 \\
\hline 1 & 0.445 & $*$ & $*$ & 0.340 & $*$ & $*$ & $*$ & * & * & $*$ \\
\hline 2 & $*$ & $*$ & * & $*$ & $*$ & $*$ & * & * & $*$ & $*$ \\
\hline 3 & $*$ & 0.653 & $*$ & $*$ & $*$ & $*$ & * & * & $*$ & $*$ \\
\hline 4 & 0.528 & $*$ & * & $*$ & $*$ & $*$ & $*$ & * & $*$ & * \\
\hline 5 & 0.527 & $*$ & * & 0.324 & $*$ & $*$ & $*$ & $*$ & $*$ & $*$ \\
\hline 6 & 0.465 & $*$ & * & 0.337 & $*$ & $*$ & * & * & * & 0.357 \\
\hline 7 & 0.490 & $*$ & * & $*$ & $*$ & $*$ & * & * & $*$ & 0.370 \\
\hline 8 & 0.481 & 0.476 & * & * & $*$ & $*$ & * & * & * & $*$ \\
\hline 9 & 0.545 & 0.365 & * & * & $*$ & $*$ & * & * & $*$ & * \\
\hline 10 & 0.559 & $*$ & * & $*$ & $*$ & $*$ & $*$ & $*$ & $*$ & * \\
\hline 11 & $*$ & $*$ & $*$ & * & $*$ & $*$ & 0.485 & $*$ & $*$ & $*$ \\
\hline 12 & $*$ & $*$ & * & $*$ & $*$ & $*$ & 0.537 & $*$ & $*$ & $*$ \\
\hline 13 & $*$ & $*$ & * & -0.338 & * & $*$ & $*$ & 0.346 & $*$ & $*$ \\
\hline 14 & $*$ & $*$ & * & -0.617 & * & $*$ & $*$ & $*$ & $*$ & $*$ \\
\hline 15 & * & $*$ & $*$ & $*$ & $*$ & $*$ & $*$ & $*$ & $*$ & $*$ \\
\hline 16 & 0.320 & 0.405 & $*$ & $*$ & $*$ & $*$ & $*$ & -0.340 & $*$ & $*$ \\
\hline 17 & $*$ & $*$ & $*$ & -0.487 & $*$ & $*$ & $*$ & $*$ & $*$ & $*$ \\
\hline 18 & $*$ & $*$ & $*$ & $*$ & $*$ & $*$ & 0.537 & $*$ & $*$ & $*$ \\
\hline 19 & $*$ & $*$ & $*$ & -0.468 & $*$ & $*$ & $*$ & $*$ & $*$ & $*$ \\
\hline 20 & $*$ & $*$ & $*$ & $*$ & $*$ & $*$ & $*$ & $*$ & $*$ & $*$ \\
\hline 21 & 0.544 & $*$ & * & $*$ & $*$ & $*$ & $*$ & $*$ & $*$ & $*$ \\
\hline 22 & $*$ & $*$ & $*$ & $*$ & $*$ & $*$ & $*$ & $*$ & 0.681 & $*$ \\
\hline 23 & $*$ & 0.450 & $*$ & $*$ & 0.432 & $*$ & $*$ & $*$ & $*$ & $*$ \\
\hline 24 & $*$ & $*$ & $*$ & $*$ & $*$ & 0.641 & $*$ & $*$ & $*$ & $*$ \\
\hline 25 & $*$ & $*$ & * & * & $*$ & 0.805 & * & $*$ & * & * \\
\hline 26 & $*$ & $*$ & $*$ & $*$ & $*$ & $*$ & $*$ & $*$ & 0.473 & $*$ \\
\hline 27 & $*$ & 0.525 & * & * & 0.343 & $*$ & * & $*$ & $*$ & * \\
\hline 28 & $*$ & $*$ & $*$ & $*$ & 0.644 & $*$ & $*$ & $*$ & $*$ & $*$ \\
\hline 29 & $*$ & * & $*$ & * & 0.545 & $*$ & * & $*$ & $*$ & $*$ \\
\hline 30 & $*$ & 0.608 & $*$ & $*$ & $*$ & $*$ & * & * & $*$ & $*$ \\
\hline 31 & 0.443 & 0.537 & * & $*$ & $*$ & * & $*$ & $*$ & * & $*$ \\
\hline 32 & $*$ & 0.784 & $*$ & $*$ & $*$ & * & $*$ & $*$ & $*$ & $*$ \\
\hline 33 & $*$ & 0.627 & $*$ & $*$ & $*$ & $*$ & $*$ & $*$ & $*$ & $*$ \\
\hline 34 & $*$ & $*$ & $*$ & $*$ & $*$ & $*$ & $*$ & 0.498 & $*$ & $*$ \\
\hline 35 & 0.422 & $*$ & $*$ & $*$ & $*$ & $*$ & $*$ & $*$ & $*$ & $*$ \\
\hline 36 & 0.465 & 0.450 & * & $*$ & $*$ & $*$ & $*$ & $*$ & $*$ & * \\
\hline 37 & $*$ & $*$ & 0.632 & * & $*$ & $*$ & $*$ & $*$ & $*$ & $*$ \\
\hline 38 & $*$ & $*$ & 0.489 & $*$ & $*$ & $*$ & $*$ & * & * & $*$ \\
\hline 39 & $*$ & $*$ & 0.506 & $*$ & $*$ & $*$ & $*$ & $*$ & $*$ & $*$ \\
\hline 40 & 0.447 & $*$ & $*$ & * & $*$ & $*$ & $*$ & $*$ & $*$ & * \\
\hline 41 & 0.521 & $*$ & * & $*$ & $*$ & $*$ & $*$ & $*$ & $*$ & * \\
\hline 42 & $*$ & $*$ & $*$ & $*$ & $*$ & $*$ & $*$ & 0.549 & $*$ & $*$ \\
\hline 43 & $*$ & $*$ & 0.522 & * & $*$ & $*$ & * & $*$ & $*$ & * \\
\hline 44 & 0.483 & * & $*$ & $*$ & * & $*$ & * & $*$ & $*$ & * \\
\hline
\end{tabular}

${ }^{\mathrm{a}}$ Rotation converged in 10 iterations, *loading less than 0.32 . 
acceptable cross loadings as well as negative loadings were removed from the matrix, 38 sentences remained loading acceptably on eight factors underlying G4SHS students' Islamic orientation. These results confirm the first hypothesis that the number of factors extracted from G4SHS students' responses differs from those of pilgrims.

Table 3 presents the descriptive statistics as well as the reliability estimates of factors underlying the 38-sentences IOS. As can be seen, the mean of IOS is 138.4 which is lower than 161.5 obtained on the 40-sentence IOS taken by pilgrims of IRS, indicating that G4SHS students are less religiously oriented than the pilgrims are. However, the standard deviation of the former (19.1) is higher than the latter (15.6), as are their reliability coefficients, i.e., 0.91 and 0.89 , respectively, indicating that the IOS is a more reliable measure of religious orientation for G4SHS students than for pilgrims. While the reliability coefficient of six factors ranges between 0.55 (theo-pacific) and 88 (social and inspirational), the concessional factor proves to be the least reliable (0.24). The eight factors together explain 39.58 percent of variance in the scale.

Table 4 presents the number of sentences which loaded acceptably on the factors underlying the IOS taken by pilgrims and G4SHS students. As can be seen, the pilgrims' first six-sentence factor represents inspirational

Table 3. Descriptive statistics and reliability estimates of the factors underlying the IOS $(N=453)$.

\begin{tabular}{lccccccc}
\hline \multicolumn{1}{c}{ Factors/Genera } & No of Ss & Mean & SD & Alpha & \multicolumn{3}{c}{ Rotation Sums of Squared Loadings } \\
\cline { 7 - 8 } 1 Social & 13 & 42.81 & 8.608 & 0.88 & 4.501 & 10.230 & 10.230 \\
2 Inspirational & 9 & 33.45 & 6.418 & 0.88 & 4.160 & 9.454 & 19.684 \\
3 Observant & 4 & 16.16 & 3.203 & 0.74 & 2.037 & 4.630 & 24.314 \\
4 Sacrificial & 2 & 6.79 & 1.927 & 0.70 & 1.506 & 3.422 & 27.736 \\
5 Humanitarian & 2 & 7.60 & 1.837 & 0.81 & 1.396 & 3.173 & 30.909 \\
6 Theo-pacific & 3 & 11.81 & 2.102 & 0.55 & 1.379 & 3.135 & 34.044 \\
7 Inquisitive & 3 & 11.74 & 2.303 & 0.24 & 1.263 & 2.871 & 36.915 \\
8 Charitable & 2 & 8.03 & 1.546 & 0.60 & 1.171 & 2.662 & 39.577 \\
Islamic Orientation & 38 & 138.40 & 19.126 & 0.91 & & & \\
\hline
\end{tabular}

Table 4. Sentences loading on the factors (F) representing Islamic genera.

\begin{tabular}{cccccc}
\hline \multicolumn{3}{c}{ Pilgrims of Imam Reza Shrine } & \multicolumn{2}{c}{ Grade Four Senior High School Students } \\
\hline $\mathbf{F}$ & Genera & Sentences & F & Genera & Sentences \\
\hline 1 & Inspirational & $27,32,33,38,39,40$ & 2 & Inspirational & 8, 16, 23, 27, 30, 31, 32, 33 \\
2 & Intrinsic & $1,2,6,7,15,34$ & & & \\
3 & Congregational & $21,26,41,44$ & & & \\
4 & Social & $5,9,10,16$ & 1 & Social & $1,4,5,6,7,9,10,21,35,36,40,41,44$ \\
5 & Ceremonial & $3,8,30,31,36$ & & & 28,29 \\
6 & Sacrificial & $23,28,29,35$ & 4 & Sacrificial & $11,12,18$ \\
7 & Theo-pacific & $11,12,18$ & 6 & Theo-pacific & 24,25 \\
8 & Humanitarian & 24,25 & 5 & Humanitarian & $13,34,42$ \\
9 & Concessional & $13,14,19,42$ & 7 & Inquisitive & $37,38,39,43$ \\
10 & Observant & 37,43 & 3 & Observant & 22,26 \\
\hline
\end{tabular}


genus explaining 7.1\% of variance in their Islamic orientation. G4SHS students' inspirational genus is, however, represented by the second factor upon which eight sentences loaded acceptably explaining $9.5 \%$ of variance in their domain. The G4SHS students' inspirational genus is thus much broader in species. Four of its constituting species represented by sentences $3,8,30$ and 31 generate the ceremonial genus which is exclusive to the pilgrims. Species 16 and 23 of G4SHS students' inspirational genus contribute to social and sacrificial genera of pilgrims' Islamic orientation, respectively. These results thus confirm the second hypothesis that the sentences constituting the factors underlying G4SHS students and pilgrims' Islamic orientation differ from each other in number.

Table 5 presents the number of words comprising the sentences which loaded acceptably on the factors extracted from the IOS administered to pilgrims and G4SHS students. As can be seen, 465 words comprise the IOS. However, when it was administered to pilgrims and G4SHS students, the number decreased from 413 to 380 , respectively. The decrease in the number of words has affected almost all linguistic categories they belong to. Out of 46 adjectives employed in the IOS, for example, 37 and 34 have described pilgrims and G4SHS students' Islamic orientation, respectively. These results confirm the third hypothesis that the number of words comprising the IOS changes when it is taken by G4SHS students and pilgrims.

Table 6 presents the correlation coefficients obtained between the IOS and its eight factors representing the genera of G4SHS students' Islamic orientation domain. As can be seen, with the exception of inquisitive genus, seven genera correlate significantly with the domain itself ranging from 0.90 (social) to 0.74 (charitable). According to Hatch and Lazaraton [26] when two measures correlate with each other at 0.80 or higher, they are measuring the same construct. If their argument holds true, then the first 13-sentence and second nine-sentence factors are basically measuring what the 38-sentence IOS measures because their correlation coefficients with the IOS are 0.90 and 0.85 , respectively. In other words, the Islamic orientation domain of G4SHS students is the same as its social and inspirational genera. None of the ten factors established by $\mathrm{K} \& \mathrm{~B}$, however, correlated as high as 0.80 or higher with the 40 -sentence IOS supporting the third hypothesis that the relationships between religious domain and its constituting genera differ from G4SHS students to pilgrims.

Table 5. Number and frequency of words comprising the IOS.

\begin{tabular}{|c|c|c|c|c|c|c|}
\hline \multirow{2}{*}{ Words } & \multicolumn{2}{|c|}{ 44-sentence IOS } & \multicolumn{2}{|c|}{ 40-sentence IOS taken by pilgrims } & \multicolumn{2}{|c|}{ 38-sentence IOS taken by G4SHS students } \\
\hline & Frequency & Percent & Frequency & Percent & Frequency & Percent \\
\hline Adjectives & 46 & 9.9 & 37 & 9.0 & 34 & 8.9 \\
\hline Adverbs & 6 & 1.3 & 4 & 1.0 & 3 & 0.8 \\
\hline Nouns & 110 & 23.7 & 96 & 23.2 & 93 & 24.5 \\
\hline Verbs & 80 & 17.2 & 72 & 17.4 & 65 & 17.1 \\
\hline Conjunctions & 38 & 8.2 & 32 & 7.7 & 29 & 7.6 \\
\hline Determiners & 43 & 9.2 & 40 & 9.7 & 37 & 9.7 \\
\hline Prepositions & 47 & 10.1 & 44 & 10.7 & 40 & 10.5 \\
\hline Pronouns & 12 & 2.6 & 11 & 2.7 & 10 & 2.6 \\
\hline Syntactic verbs & 6 & 1.3 & 5 & 1.2 & 3 & 0.8 \\
\hline Abbreviations & 1 & 0.2 & 1 & 0.2 & 1 & 0.3 \\
\hline Names & 16 & 3.4 & 16 & 3.9 & 15 & 3.9 \\
\hline Para-adverbs & 4 & 0.9 & 4 & 1.0 & 2 & 0.5 \\
\hline Particles & 56 & 12.0 & 51 & 12.3 & 48 & 12.6 \\
\hline Total & 465 & 100.0 & 413 & 100.0 & 380 & 100.0 \\
\hline
\end{tabular}


Table 6. Correlations between the IOS measuring the domain of Islamic orientation and its eight genera.

\begin{tabular}{|c|c|c|c|c|c|c|c|c|c|c|}
\hline No & Genera & IOS & 1 & 2 & 3 & 4 & 5 & 6 & 7 & 8 \\
\hline & IOS & 1 & $0.897^{* *}$ & $0.849^{* *}$ & $0.705^{* *}$ & $0.639^{* *}$ & $0.533^{* *}$ & $0.419^{* *}$ & -0.014 & $0.410^{* *}$ \\
\hline 1 & Social & $0.897^{* *}$ & 1 & $0.704^{* *}$ & $0.580^{* *}$ & $0.483^{* *}$ & $0.371^{* *}$ & $0.258^{* *}$ & $-0.156^{* *}$ & $0.250^{* *}$ \\
\hline 2 & Inspirational & $0.849^{* *}$ & $0.704^{* *}$ & 1 & $0.482^{* *}$ & $0.570^{* *}$ & $0.362^{* *}$ & $0.268^{* *}$ & $-0.196^{* *}$ & $0.227^{* *}$ \\
\hline 3 & Observant & $0.705^{* *}$ & $0.580^{* *}$ & $0.482^{* *}$ & 1 & $0.427^{* *}$ & $0.377^{* *}$ & $0.210^{* *}$ & -0.057 & $0.245^{* *}$ \\
\hline 4 & Sacrificial & $0.639^{* *}$ & $0.483^{* *}$ & $0.570^{* *}$ & $0.427^{* *}$ & 1 & $0.351^{* *}$ & $0.240^{* *}$ & $-0.122^{* *}$ & $0.155^{* *}$ \\
\hline 5 & Humanitarian & $0.533^{* *}$ & $0.371^{* *}$ & $0.362^{* *}$ & $0.377^{* *}$ & $0.351^{* *}$ & 1 & $0.183^{* *}$ & -0.019 & $0.404^{* *}$ \\
\hline 6 & Theo-pacific & $0.419^{* *}$ & $0.258^{* *}$ & $0.268^{* *}$ & $0.210^{* *}$ & $0.240^{* *}$ & $0.183^{* *}$ & 1 & 0.085 & $0.199^{* *}$ \\
\hline 7 & Inquisitive & -0.014 & $-0.156^{* *}$ & $-0.196^{* *}$ & -0.057 & $-0.122^{* *}$ & -0.019 & 0.085 & 1 & $0.192^{* *}$ \\
\hline 8 & Charitable & $0.410^{* *}$ & $0.250^{* *}$ & $0.227^{* *}$ & $0.245^{* *}$ & $0.155^{* *}$ & $0.404^{* *}$ & $0.199^{* *}$ & $0.192^{* *}$ & 1 \\
\hline
\end{tabular}

\section{Discussions}

The cognitive analysis of the IOS administered to G4SHS students shows that their domain of Islamic orientation consists of 206 schema types. The ever-evolving formation and application of these schema types in the students' life in different frequency and specific syntactic order brings up 38 species which explain the domain within eight genera, i.e., social, inspirational, observant, sacrificial, humanitarian, theo-pacific, inquisitive, and charitable. A comparative analysis of G4SHS students' Islamic genera with those of pilgrims, i.e., Inspirational, Intrinsic, Congregational, Social, Ceremonial, Sacrificial, Theo-pacific, Humanitarian, Concessional, and Observant, shows that they differ from each other in terms of their constituting schema types, and species.

G4SHS students' social genus, for example, comprises 94 schema types and 13 species. It is the most important genus because it explains the highest percentage of variance in the students' Islamic orientation, i.e. 10.32\%. Among the 30 noun schema types constituting the genus, three reveal its scope because each of them contributes to the formation of genus three times, i.e., "life", "mosque" and "religion." These three schemata along with the remaining 27 nouns are described via 12 adjective schema types among which "religious" and "social" stand out due to their being employed three and two times, respectively. Their relatively high frequency not only highlights their linguistic and statistical importance in social genus but also explains what the species constituting the genus are about.

Species 10, "to consider mosques as the most important places where good social relationships are formed", for example, is pivotal to G4SHS students' social genus because it has the highest loading (0.59) on the first factor which represents the genus. Furthermore, they "attend mosques if unavoidable circumstances do not prevent it" (species 9) not because they pray or improve their spiritual intelligence in these places but the mosques provide them with good sites where they can establish relationships which are first and foremost social in nature. Similar to species 10, species 9 occupies a prototypical status in the genus due to its second highest loadings (0.55) on the first factor upon which it loads acceptably.

The Imam Reza Shrine in Mashhad plays a significant role in Shiite Muslims' Islamic orientation because it "attracts more than 12 million pilgrims a year. That's more even than Mecca in Saudi Arabia, making it the Islamic world's busiest holy site" [27]. As G4SHS students grow older and/or attend and pray in the shrine, they develop intrinsic and congregational genera out of the six species which contribute only to their social genus within the educational setting of senior high schools in Mashhad.

The pilgrim-specific intrinsic genus in K \& B's study consists of six species, i.e., 1, 2, 6, 7, 15, and 34, among which species seven, "to read literature about faith or religion" combines with 12 species to characterize G4SHS students' social genus. This particular species has the greatest contribution to pilgrims' intrinsic genus due to its highest loading on the second factor representing the genus. Species two, "to be keenly aware of the presence of God or the Divine Being” which does not contribute to any of the eight genera constituting G4SHS students' Islamic orientation explains why a species of G4SHS students' social genus gains an intrinsic dimension for pilgrims.

While G4SHS students "read literature about faith or religion” (species seven) in order to attend mosques and 
religious ceremonies where they can form good social relationships with others, pilgrims "read literature about faith or religion" to become "keenly aware of the presence of God or the Divine Being" (species two) as they pray in the presence of other pilgrims who "pray because everyone is taught to pray" (species 15). In other words, pilgrims utilized species two and fifteen and combined them with the students' four social species to motivate themselves intrinsically. (Species two and fifteen show no relevance to G4SHS students' Islamic orientation because they did not load on any factors representing their eight religious genera.)

In addition to intrinsic genus, pilgrims derive their specific congregational genus from G4SHS students' social species 21,41 , and 44 . The genus derives its name from species 41 , "to give priority to everyday congregations", having the highest loading (0.58) on the factor representing the genus in K \& B's study. The genus involves species 21 through which pilgrims not only become members of mosques to establish themselves in the community but also "attach more importance to religious trips than to tourism" (species 44).

While pilgrims do charitable work like supporting the orphans (species 26), become members of mosques (species 21), prioritize everyday congregations (species 41), and attach more importance to religious trips (species 44) as parts and parcels of their congregational genus, G4SHS students decongregationize species 26 and combine it with species 22, "to do charitable work like supporting the orphans" to create their own studentspecific charitable genus of Islamic orientation. In other words, pilgrims consider charitable activities as part of their congregational responsibility whereas G4SHS students adopt them as species of a distinct genus which needs not to be mosque-dependent.

Not only do the two congregational species bring to light the G4SHS student-specific charitable genus of Islamic orientation, i.e., 22 and 26, but also two species of pilgrims' concessional genus, i.e., 13 and 42, detach themselves from its other two species, i.e., 14 and 41, and combine with their intrinsic species 34 to generate the G4SHS student-specific inquisitive genus. The inquisitive G4SHS students "obtain information on other religions besides Islam" (species 42) and "do a research before accepting" (species 34) it to "lead a moral life without attaching any importance to what religion one believes" (species 13). When students grow up and/or become pilgrims they combine species 13 and 42 with 14, "in spite of being a religious person, religious considerations should not be allowed to influence everyday affairs" and 19, "to accept that in spite of believing in religion, there are many more important things in life" to render their inquisitive genus concessional for pilgrims.

Unlike G4SHS students' inquisitive genus whose number of species increases from three to four to reflect its broader life-based scope as a concessional genus for pilgrims, their inspirational genus consists of nine species, i.e., 3, 8, 16, 23, 27, 30, 31, 32 and 33, most of which change to ceremonial (3, 8, 30 and 31), sacrificial (23), and social (16) genera, for pilgrims. These results show that schemata acquire additional meanings in terms of the species and genera to which they contribute in combination with each other. While the schema "ceremony", for example, serves G4SHS students' inspirational genus in nine spices, it contributes to the pilgrims' ceremonial genus when it deals with "mourning in the months of Moharram and Safar (species 3) and "celebrating the birthdays of the Prophet and his household" (species 30). It also contributes to pilgrims' social genus when they "take part in religious ceremonies because they are congenial social activities" (species 16).

And finally, among the genera forming the domain of Islamic orientation, humanitarian and theo-pacific genera stay stable in terms of their constituting species for both G4SHS students and pilgrims. Since pilgrims differed in terms of their educational levels, a future research project is required to find out whether the genera will have the same species if the IOS is administered to participants such as undergraduate university students. Although G4SHS students and pilgrims' humanitarian and theo-pacific genera consist of the same species, they relate differently to other genera of Islamic orientation. While G4SHS students' humanitarian and charitable genera, for example, correlate the highest with each other $(r=0.40, \mathrm{p}<0.01)$, pilgrims' humanitarian genus correlates the highest with their sacrificial genus $(r=0.41, \mathrm{p}<0.01)$. Future research projects are also required to find out how these genera relate to variables such as English language achievement.

\section{Conclusions}

Few researchers have approached questionnaires such as the IOS from a theoretically sound basis. In Dornyei's [28] words, "the practice of questionnaire design/use has remained largely uninformed by theory" (pp. 3-4), leading to their being named differently as "batteries", “checklists", "forms", "indexes/indicators", "inventories", “opinnionaires”, “profiles”, “scales”, “schedules”, “sheets”, "studies”, “surveys”, and "tests” [29]. The present study thus informs researchers in various fields by addressing the IOS from the microstructural approach of 
schema theory. The approach is based on the assumption that the words comprising the 44 items of IOS play the most important role in securing its content validity as a psychological measure.

The concepts represented by the words, i.e., schemata, activate specific mental images in the minds of IOS takers which combine with each other within the linguistic context of a specific item to produce a broader concpet called species. The takers' evaluation of species within the range of points brought up by the alternatives of items indicate which species can be combined with each other or load on a specific statistical factor to identify another concept, i.e., genus, whose scope is broader than its constituting species. The genera and their constituting species and schemata, therefore, reveal the nature of the domain measured by the IOS.

The IOS is a designer-specific psychological measure whose content as well as construct validity depends on who takes it simply because its constituting words, items and factors represent different schemata, species and genera for participants coming from different educational backgrounds, religious practices and social affiliations, to name a few. The results of this study did, for example, show that the Islamic orientation of IRS pilgrims differs from that of G4SHS students in terms of its constituting schemata, species and genera as did the domain of teacher effectiveness among grade three senior high school and G4SHS students [30] [31]. The administration of the IOS to university students should therefore provide further evidence to reject or confirm the explanatory power of schema theory in designing and validating psychological measures.

\section{References}

[1] Khodadady, E. and Bagheri, N. (2014) Development and Validation of an Islamic Religious Orientation Scale with Pilgrims of Imam Reza Shrine. Journal of Arts and Humanities, 3, 37-50.

[2] Allport, G.W. and Ross, J.M. (1967) Personal Religious Orientation and Prejudice. Journal of Personality and Social Psychology, 5, 432-443. http://dx.doi.org/10.1037/h0021212

[3] Herek, G.M. (1987) Religious Orientation and Prejudice: A Comparison of Racial and Sexual Attitudes. Personality and Social Psychology Bulletin, 13, 34-44. http://dx.doi.org/10.1177/0146167287131003

[4] Almeida, C.D.S. (2006) Religious Orientation and Pressure in Undergraduate Engineering Students. Unpublished Master's Thesis, University of the Witwatersrand, Johannesburg.

[5] Weiten, W. (1988) Pressure as a Form of Stress and Its Relationship to Psychological Symptomatology. Journal of Social and Clinical Psychology, 6, 127-139. http://dx.doi.org/10.1521/jscp.1988.6.1.127

[6] Weiten, W. (1998) Pressure, Major Life Events and Psychological Symptoms. Journal of Social Behaviour and Personality, 13, 51-68.

[7] Ghorbani, N., Watson, P.J., Ghramaleki, A.F., Morris, R.J. and Hood, R.W. (2002) Muslim-Christian Religious Orientation Scales: Distinctions, Correlations, and Cross-Cultural Analysis in Iran and the United States. The International Journal for the Psychology of Religion, 12, 69-91. http://dx.doi.org/10.1207/S15327582IJPR1202 01

[8] Kirkpatrick, L.A. (1989) A Psychometric Analysis of the Allport-Ross and Feagin Measures of Intrinsic-Extrinsic Religious Orientation. In: Lynn. M.L. and Moberg, D.O., Eds., Research in the Social Scientific Study of Religion: A Research Annual, JAI, Stamford, CT, Vol. 1, 1-31.

[9] Brewczynski, J. and MacDonald, D.A. (2006) Confirmatory Factor Analysis of the Allport and Ross Religious Orientation Scale with a Polish Sample. The International Journal for the Psychology of Religion, 16, 63-76. http://dx.doi.org/10.1207/s15327582ijpr1601 6

[10] Feagin, J.R. (1964) Prejudice and Religious Types: A Focused Study of Southern Fundamentalists. Journal of the Scientific Study of Religion, 4, 3-13. http://dx.doi.org/10.2307/1385200

[11] Khodadady, E. and Golparvar, E. (2011) Factors Underlying Religious Orientation Scale: A Methodological Approach. Ilahiyat Studies: A Journal on Islamic and Religious Studies, 2, 215-235.

[12] Khodadady, E. and Saadi, N.S. (2015) Religious Orientation and English Language Proficiency. International Journal of Psychology and Behavioral Sciences, 5, 35-47.

[13] Fairchild, M. (2014) Church Worship Service. About Religion. http://christianity.about.com/od/churchandcommunity/ss/churchservice.htm

[14] Khodadady, E. and Bagheri, N. (2012) Construct Validation of a Modified Religious Orientation Scale within an Islamic Context. International Journal of Business and Social Science, 3, 237-246.

[15] Khodadady, E., Mousavi, E.G. and Sarraf, F. (2012) Age and Educational Level and Their Relationship with Religious Orientation. International Journal of Business and Social Science, 3, 291-302.

[16] Newby, G.D. (2002) A Concise Encyclopedia of Islam. Oneworld Publications, Oxford. 
[17] Al-Razi, F. (1210) Al-Tafsir al-Kabir V12. Egypt: al-Matba’ah al-Bahiyah al-Misriyah

[18] Ghomi, A. (2005) Mafatih al-jenan (The Keys to the Gardens of Heaven). Shaker Cultural and Publication Institute, Ghom.

[19] Al-Islam Organization (2015) Significance of the Months of Muharram \& Safar in Islam. http://www.alislam.org/print/book/export/html/21909

[20] Ali, K. and Leaman, O. (2008) Islam: The Key Concepts. Routledge, New York.

[21] Al-Seestani, S.A.A.H. (1996) Contemporary Legal Ruling in Shia Law. Islamic Mobility, Montreal.

[22] Khodadady, E. (2013) Research Principles, Methods and Statistics in Applied Linguistics. Hamsayeh Aftab, Mashhad.

[23] Tabachnick, B.G. and Fidell, L.S. (2007) Using Multivariate Statistics. 5th Edition, Pearson, Boston.

[24] Kaiser, H. (1974) An Index of Factorial Simplicity. Psychometrika, 39, 31-36. http://dx.doi.org/10.1007/BF02291575

[25] DiLalla, D.L. and Dollinger, S.J. (2006) Cleaning up Data and Running Preliminary Analyses. In: Leong, F.T.L. and Austin, J.T., Eds., The Psychology Research Handbook: A Guide for Graduate Students and Research Assistants, Sage, Thousand Oaks, 241-253. http://dx.doi.org/10.4135/9781412976626.n16

[26] Hatch, E. and Lazaraton, A. (1991) The Research Manual: Design and Statistics for Applied Linguistics. Heinle \& Heinle, Boston.

[27] Dow Jones \& Company (2013) Giving Back at the Shrine of Imam Reza. Online Wall Street Journal. http://online.wsj.com/article/SB118056219190419132.html

[28] Dornyei, Z. (2003) Questionnaires in Second Language Research: Construction, Administration, and Processing. Lawrence Erlbaum Associates, Mahwah.

[29] Aiken, L. (1997) Questionnaires and Inventories: Surveying Opinions and Assessing Personality. John Wiley, New York.

[30] Khodadady, E., Fakhrabadi, G.Z. and Azar, K.H. (2012) Designing and Validating a Comprehensive Scale of English Language Teachers' Attributes and Establishing Its Relationship with Achievement. American Journal of Scientific Research, 82, 113-125.

[31] Khodadady, E. and Dastgahian, B.S. (2015) Teacher Effectiveness, Educational Grade and English Achievement. Theory and Practice in Language Studies, 5, 1552-1562. http://dx.doi.org/10.17507/tpls.0508.03 